\title{
LA IMAGEN DINÁSTICA DE LOS JULIO-CLAUDIOS EN EL FORO DE SE- GOBRIGA (SAELICES, CUENCA. CONUENTUS CARTHAGINENSIS)
}

\author{
JUAN MANUEL ABASCAL \\ Universidad de Alicante \\ ROSARIO CEBRIÁN \\ Equipo Científico de Segobriga \\ TERESA MONEO \\ Equipo Científico de Segobriga
}

\begin{abstract}
Las inscripciones, esculturas y hallazgos arqueológicos de Segobriga han permitido determinar la probable existencia de una estancia de culto dinástico para los príncipes JulioClaudios en el foro de la ciudad. Este culto debe guardar relación con la gratitid de la ciudad hacia la familia imperial tras la creación del municipium en época de Augusto.
\end{abstract}

The inscriptions, sculptures and others archaeological discoveries in Segobriga enabled us to determine the probable presence of a Dynastic CultRoom for the Julio-Claudian Princes and his family at the Forum of the city. This cult is the greatest evidence of the gratitude of the city after the concession of municipal rights in Augustean times.

En el mes de agosto de 1999, durante la excavación de una estancia cercana al foro de la antigua ciudad romana de Segobriga, apareció un retrato femenino en mármol, de dimensiones ligeramente superiores a las naturales, que podría identificarse con Agrippina Maior. Un año después, y a pocos metros del anterior hallazgo pero en otro edificio, apareció un togado capite uelato que había sido aprovechado como cimiento para un muro. Ambas esculturas, que vienen a sumarse al rico conjunto ya conocido anteriormente en Segobriga, deben formar parte de programas iconográficos cercanos en el tiempo y quizá procedan de un mismo lugar. En las páginas que siguen haremos una presentación preliminar de estos hallazgos a la espera de que las nuevas excavaciones en esta zona de la ciudad aclaren en la medida de lo posible la ubicación original de ambas piezas.

\section{RETRATO DE AGRIPPINA MAIOR (FIG. 2 y 5-8)}

\section{l.1. Lugar de hallazgo}

Frente al edificio identificado hasta ahora como la basílica forense de Segobriga (ALMAGRO GORBEA Y ABASCAL, 1999, pp.
95-98), cerca del acceso septentrional de la ciudad, se procedió en 1999 a excavar un amplio solar contiguo a las llamadas "termas del teatro», que había sido en época renacentista objeto de expolio para extraer sillares ${ }^{1}$. La excavación puso al descubierto un edificio rec-

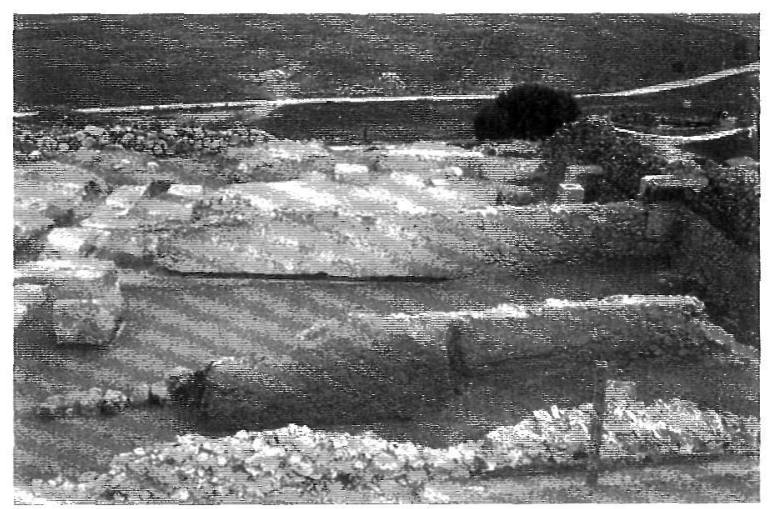

Figura 1. Vista general de la zona del hallazgo al término de la excavación.

\footnotetext{
${ }^{1}$ La excavación fue dirigida por los Dres. Martín Almagro Gorbea y Juan Manuel Abascal; de la excavación de este sector se hizo cargo la arqueóloga $D^{a}$ Teresa Moneo con la coordinación sobre el terreno de la Dra. Rosario Cebrián. EI estudio de los materiales cerámicos citados en este trabajo es obra del arqueólogo D. Daniel Sanfeliu. Las excavaciones fueron financiadas a través del convenio suscrito por la Consejería de Cultura de la Junta de Comunidades de Castilla-La Mancha con el Instituto Nacional de Empleo y se prolongaron desde el 1 de julio al 31 de diciembre de 1999.
} 


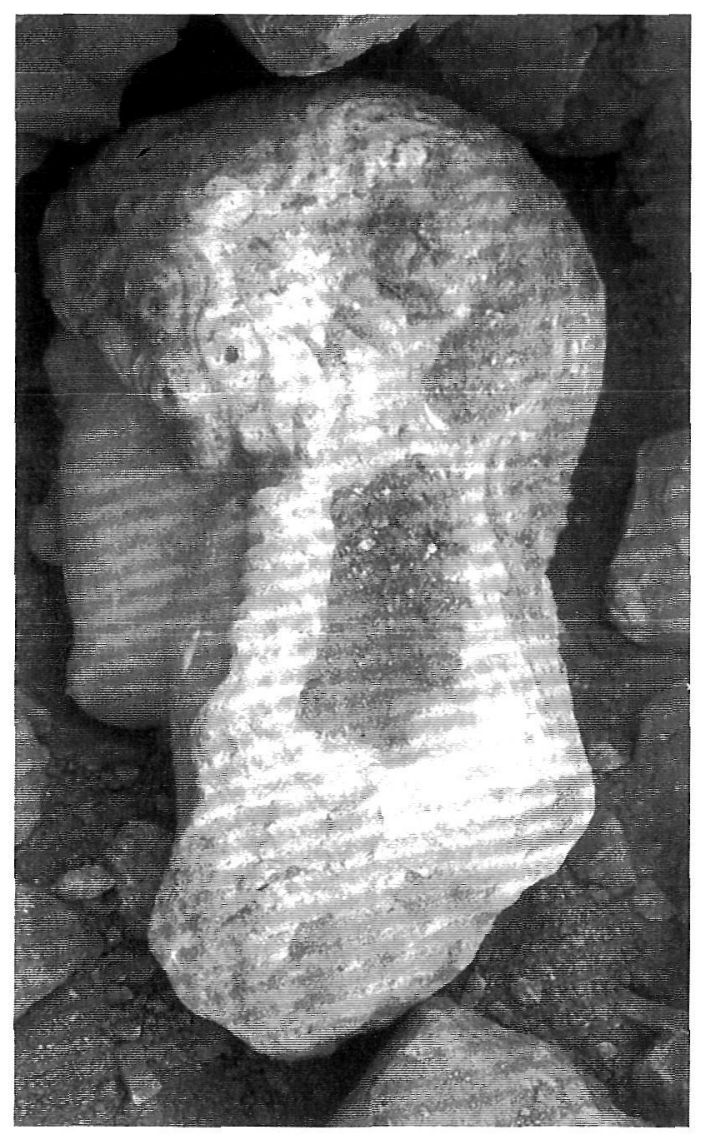

Figura 2. Detalle del hallazgo.

tangular de 18,36 x 11,76 metros, que presentaba en el interior las basas de sillares cuadrados de lo que había sido una columnata perimetral interna. Hacia el sur este edificio se ensancha con un cuerpo trapezoidal de 15,26 $m$ de anchura, quizá abierto a la calle que lo separaba de la basílica forense.

La construcción alterna lienzos de opus caementicium con pilares de sillería para reforzar el conjunto, especialmente en las esquinas del lado norte, en donde la inclinación del terreno natural obligó a reforzar la construcción y en donde sólo se pudo documentar el expolio de los sillares. Habida cuenta de la pendiente sobre la que se construyó, hubo de realizarse una nivelación previa del terreno; aunque estos rellenos de nivelación fueron alterados en las reformas posteriores, en las grietas entre la roca pudieron documentarse algunos materiales que han permitido establecer una datación post quem para el conjunto.

I.1.a. La fecha de construcción del edificio (Fase I) puede calcularse por los materiales recogidos en las tierras de nivelación del solar y por los objetos recuperados en sus zanjas de cimentación.
En la zanja exterior tallada en la roca en el lado contiguo a las termas de teatro (UE 2603), se recuperó un denario de bolskan de época sertoriana algo gastado; en las grietas de la roca bajo los rellenos de nivelación del sector 3 aparecieron fragmentos de cerámica pintada de época augustea, y en el nivel inferior de estos rellenos (UE 2254) apareció también un plato de cerámica de imitación de barniz negro con restos de pintura roja; junto a él se recogió un fragmento de plato de tipo «rojo pompeyano". En la parte inferior del sector 2 (UE 2221) apareció un denario de Augusto (RIC 1 207). El material cerámico de estos rellenos tiene una amplia presencia de sigillatas itálicas.

I.1.b. En una segunda etapa (Fase II), el recinto fue compartimentado en cuatro salas independientes y adaptado para tabernae, trasladando el acceso, ahora cuádruple, al costado $W$. Con tal fin se desmontaron los pilares interiores que obstruían ahora el paso por los nue-
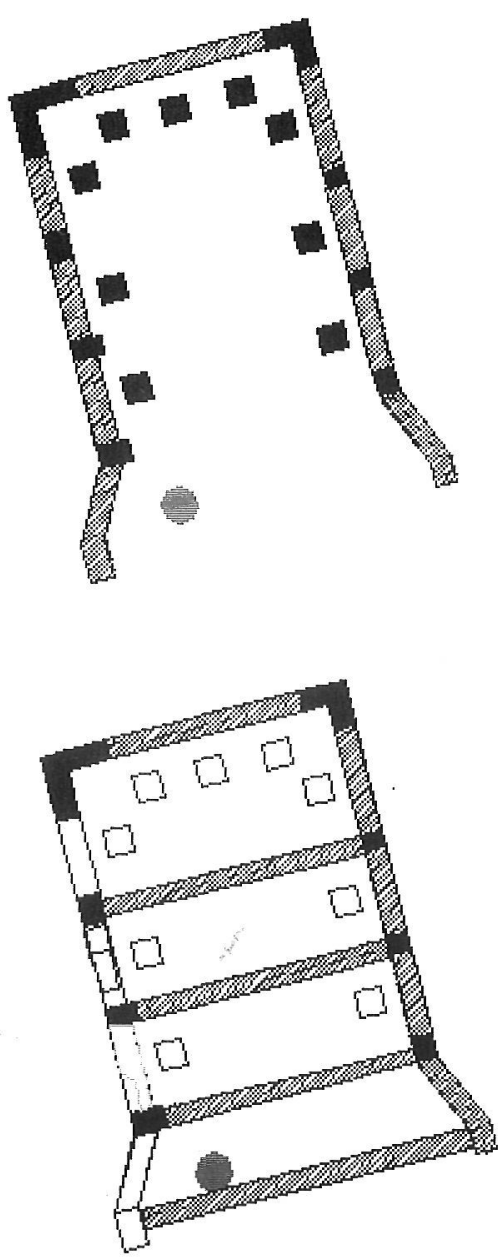

Figura 3. Lugar del descubrimiento de la cabeza de Agrippina. Fases I (arriba) y II (abajo) con indicación del hallazgo. 


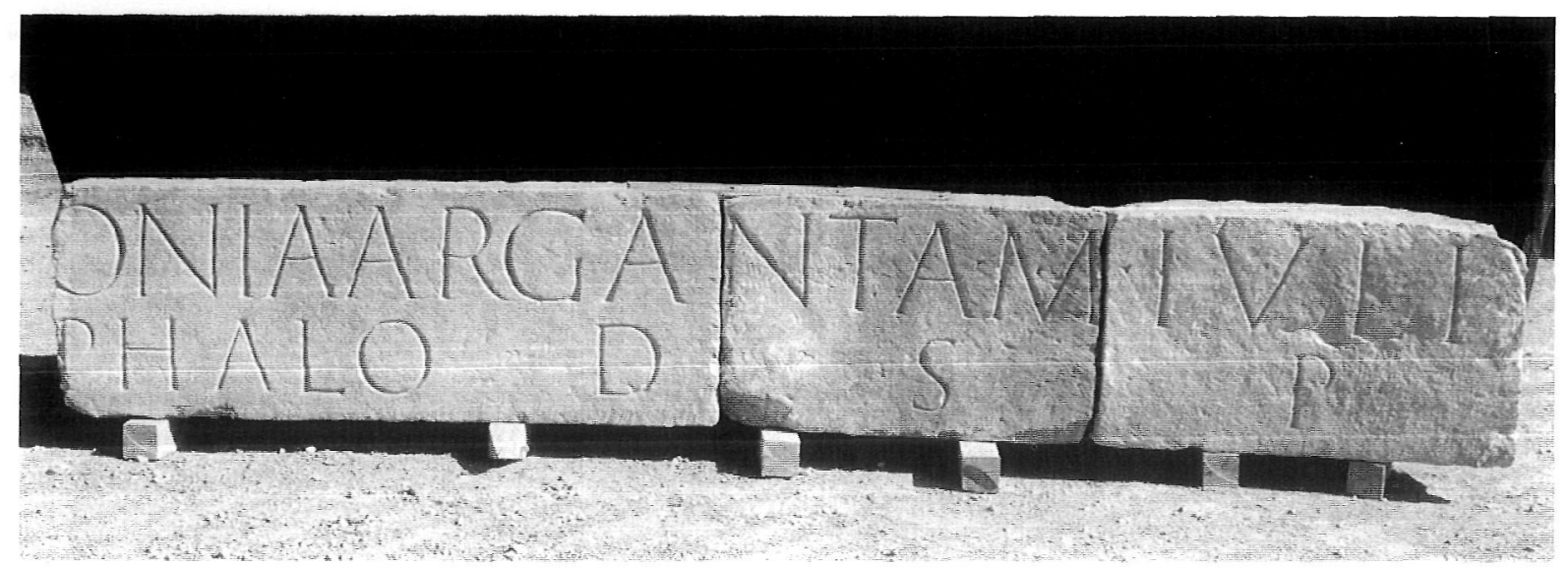

Figura 4. Inscripción monumental reaprovechada en la construcción de la segunda Fase.

vos umbrales y se elevaron los suelos (UE 2214 en la estancia 2) con nuevas nivelaciones. Las paredes que separan las cuatro estancias están construidas con una mampostería montada sobre tinglado de madera del que han quedado las huellas del contramolde al haber desaparecido las vigas que lo formaban.

El muro que separaba las estancias $1 \mathrm{y}$ 2 reaprovechó una inscripción monumental (Figura 4$)^{2}$ perteneciente a un edificio que había dejado de cumplir su función original. Los bloques de la inscripción, de excesivo peso para la resistencia del muro, cayeron sobre el nivel de ocupación de la taberna, en donde se recuperaron con las letras rellenas de argamasa; allí aparecieron también un capitel corintio y un columna estriada que también habían sido reaprovechados en la construcción.

En uno de los rellenos de esta fase, por debajo del nivel de circulación de la estancia 1 $(-57 \mathrm{~cm}$ de punto 0$)$, se recuperó la cabeza de mármol objeto de estas notas; formaba parte de un conjunto de tierras (UE 2173) que albergaba también fragmentos de tejas y ladrillos en una gruesa capa de más de $40 \mathrm{~cm}$ de potencia. La referencia temporal más moderna de todo el conjunto es un fragmento cerámico de sigillata africana tipo C (TSC) de pleno siglo III, quizá perteneciente a una forma Hayes 50 .

Este relleno constituía la última capa de colmatación de la estancia 1 por debajo de la línea de umbral (-49 $\mathrm{cm}$ de punto 0 ), por lo que la escultura y el resto de los materiales debieron arrojarse aquí en algún momento del siglo III d.C., para nivelar el suelo de la estancia y permitir su nuevo uso.

I.1.c. Las estancias 3 y 4 aún fueron de nuevo compartimentadas en época posterior (Fase III), como muestran los muros de mampostería mal trabada que se documentaron allí.

\section{I.2. Descripción y estado de conservación}

La cabeza femenina apenas sufrió desperfectos al ser arrojada al nivel de relleno de la sala, y su grado de conservación es bastante aceptable, con algunas erosiones superficiales especialmente en el rostro.

Está fabricada en mármol blanco de grano grueso y sus dimensiones máximas son 34 $\mathrm{cm}$ de altura, $24,5 \mathrm{~cm}$ de anchura y un grosor de $21 \mathrm{~cm}$ hasta la parte posterior del peinado. La parte inferior del cuello está tallada en forma de cuña redondeada, para insertar la cabeza en una figura de cuerpo completo.

El rostro de la imagen está pulido mientras en el resto del contorno sólo aparece alisado. Presenta la boca cerrada, con la comisura de los labios muy marcada; las pupilas estaban pintadas, pues no queda perforación alguna para insertar piezas. La nariz es recta, con un ligero resalte en la parte superior, y los ojos son almendrados y regulares. Bajo el peinado sobresalen los lóbulos de ambas orejas. Los pómulos están muy marcados, la barbilla poco señalada y el cuello es largo.

Sobre la frente, el cabello aparece dividido en dos partes con raya central muy fina. El peinado es ondulado y terminado en rizos con perforación central. La parte posterior del cabello está señalada con incisiones poco elaboradas; a la altura de las orejas cuelgan dos bucles de pelo de $11,5 \mathrm{~cm}$ de longitud que re-

\footnotetext{
${ }^{2}$ La inscripción dice: $[-c .18$ - Sempr]onia $\cdot$ Arganta $\cdot M($ arcus $)$ - Iuliu[s]/[-c. 18-Ce]phalo $\cdot \mathrm{d}(\mathrm{e}) \cdot \mathrm{s}(\mathrm{ua}) \cdot \mathrm{p}$ (ecunia) - (?). Cfr. Abascal 2000 (e.p.).
} 


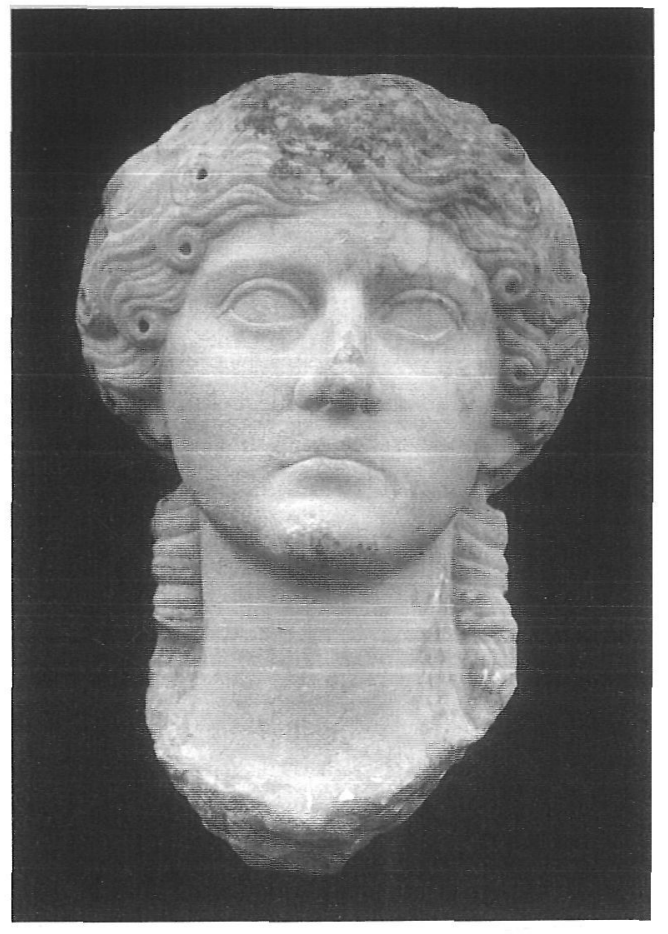

Figura 5. Retrato de Agrippina. Vista frontal.

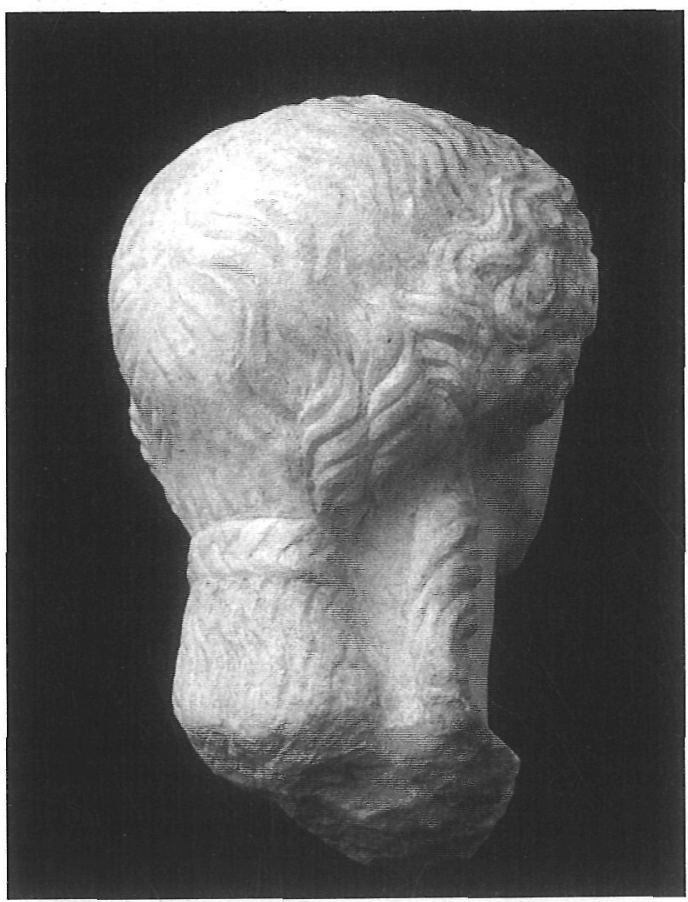

Figura 6. Retrato de Agrippina. Vista posterior.

corren el cuello; por detrás el pelo aparece recogido en una coleta que llega hasta la parte inferior del cuello, sujeta con una cinta trenzada de $3 \times 9 \mathrm{~cm}$.

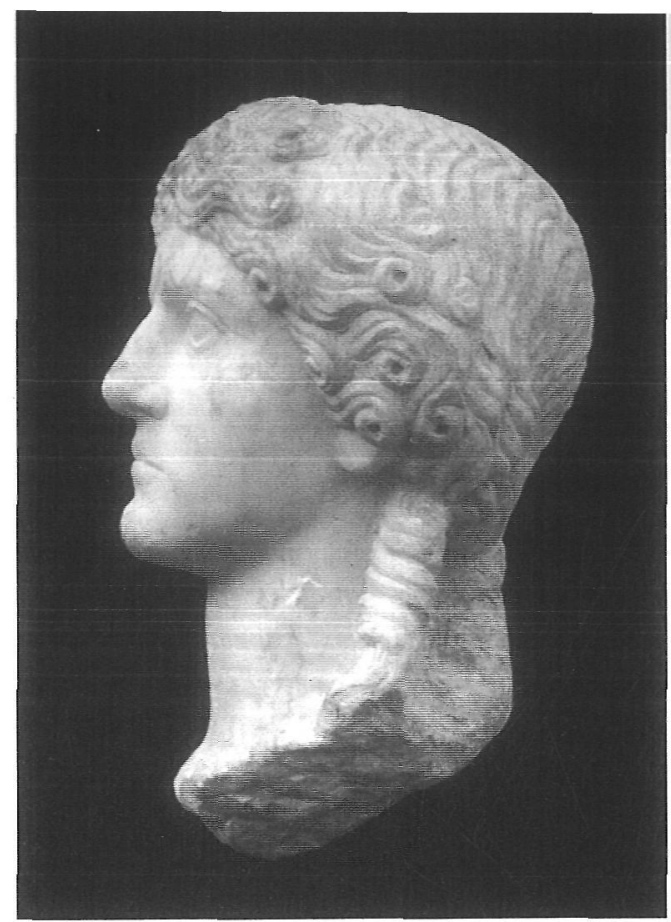

Figura 7. Retrato de Agrippina. Lateral izquierdo.

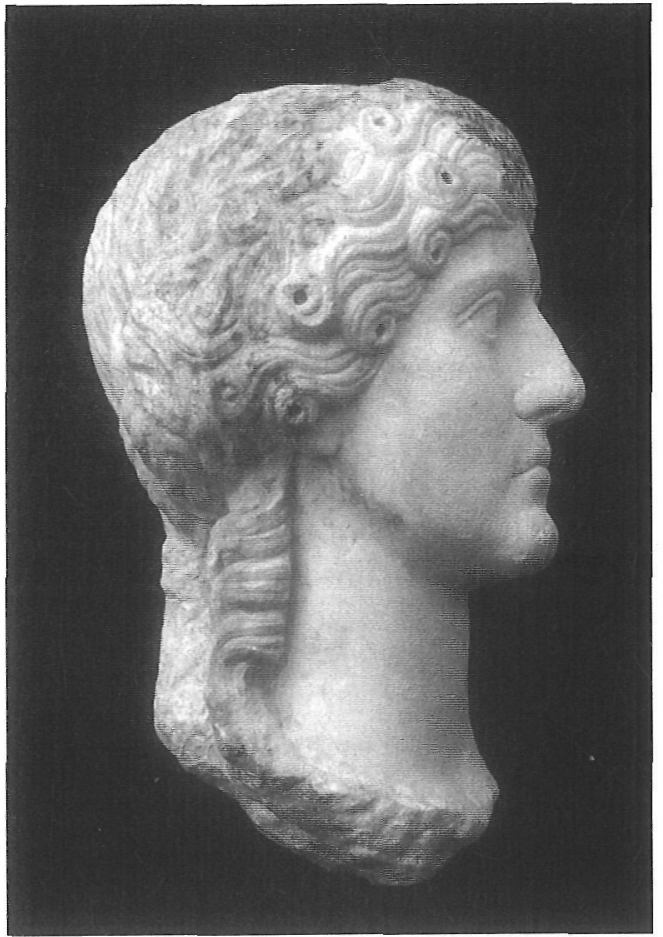

Figura 8. Retrato de Agrippina. Lateral derecho.

\section{I.3. Identificación y cronología}

El lugar de descubrimiento de la pieza no permite una identificación inmediata de la figura; podría tratarse de una retrato perteneciente a un programa decorativo más amplio situado en la parte monumental de Segobriga y del que 
hay otras evidencias, pero también podríamos estar ante un retrato privado que tomara como modelo una imagen imperial, un fenómeno conocido y sobradamente discutido (POLASCHEK 1973; TRILLMICH 1984, pp. 135 ss. con el resto de la bibliografía).

A primera vista, la figura representada en el retrato responde al modelo establecido para Agrippina Maior, la hija de Agrippa y Julia (14 a.C.- 33 d.C.) y nieta de Augusto, casada con Germánico hasta la muerte de éste en Antioquía (TAC., Hist. 2, 83, 2) el año 19 d.C. (TAC., Hist. 2, 71-72) y muerta en el exilio de la isla de Pandateria en el golfo de Nápoles (SUET., Tib. 53; SHOTERR 2000). Sus imágenes se popularizaron con la llegada de su hijo Calígula al trono (37-41 d.C.) y constituyó un elemento habitual en los programas decorativos que representan a la familia Caesaris en muchas ciudades.

El retrato "clásico" de Agrippina puede reconocerse en el sestercio póstumo acuñado en torno al año 38 d.C. por Calígula, en que aparece de perfil con un carpentum funerario en el reverso (RIC I2 55 ; TRILLMICH 1978, pp. 10-17 y 99-142; JUCKER 1980; LICHOCKA 1984 y 1986). En escultura, el prototipo puede reconocerse en el retrato conservado en la Stanza degli Imperatori de los Museos $\mathrm{Ca}$ pitolinos (FITTSCHEN-ZANKER 1983, pp. 56, lám. 4-5; BOSCHUNG 1993, pp. 61-62), aunque la imagen debe considerarse fijada a finales de la época augustea (PolAscheK 1973, pp. $36 \mathrm{ss}$.).

Se conserva un buen número de retratos de Agrippina Maior (POLASCHEK 1973; TRILLMICH 1978, pp. 10-17 y 99-142; id., 1984; FITTSCHENZANKER 1983, p. 5, nota 3; WOOD 1988; TANSINI 1995), algunos de ellos en Hispania (TRILLMICH 1984, pp. 148-151). No todos responden a un mismo modelo ni en las proporciones ni en la ejecución de los detalles, aunque se respetaron siempre una serie de pautas iconógráficas fijadas en los prototipos.

A la vista de los ejemplos conocidos, el nuevo retrato de Segobriga guarda una extraordinaria similitud con los retratos de Agrippina Maior de Coimbra (HERTEL 1981, p. 266, lám. $30 \mathrm{c}-d$ y 32) y Samos (TÖLLE-KASTENBEIN 1974, p. 174, lám. 335; TRILLMICH 1984, p. 151, lám. 29c-d), dos ejemplos cuya proximidad ya fue establecida por Trilmich y que derivan del modelo de la Agrippina Maior de los Museos Capitolinos (TRILLMICH 1984, pp. 148151).

El retrato conservado en el Museo Machado de Castro de Coimbra y el nuevo retrato segobrigense guardan una extraordinaria semejanza. Ambos comparten un mismo tratamiento del rostro y de la parte posterior del peinado; sin embargo, la nueva cabeza de Segobriga se asemeja más al ejemplar de Samos en el ligero ladeamiento hacia la izquierda y en el tratamiento de los rizos en la parte delantera del cabello. Interesa destacar, sin embargo, que el mejor referente formal para el ejemplar de Segobriga es justamente el retrato de Agrippina Maior del sestercio acuñado en época de Calígula, con el que coincide en el tratamiento de los rizos laterales que caen junto al cuello. Con estos argumentos pensamos que el retrato de Segobriga debe identificarse con Agrippina Maior en tanto en cuanto sus referentes formales también lo sean.

No existe posibilidad alguna de fechar con datos de la excavación el nuevo retrato. Al formar parte de un nivel de relleno su datación depende directamente de los paralelos formales, es decir, de las imágenes de los Museos Capitolinos, Coimbra y Samos principalmente y del retrato de $R /\left.C\right|^{2}, 55$. Según esto, la pieza podría datarse en el reinado de Calígula o en los primeros años del reinado de Claudio, es decir circa 37-50 d.C.

\section{TOGADO CAPITE VELATO (FIG. 11 y 13-16)}

\section{II.1. Lugar de hallazgo}

El descubrimiento tuvo lugar el 7 de septiembre del año 2000 en una estancia contigua a la llamada "basílica forense» de Segobriga, a corta distancia de donde un año antes había aparecido el retrato de Agrippina ${ }^{3}$.

El objeto de la excavación era descargar de presión el muro oriental de aquel edificio para proceder más adelante a su restauración, suponiendo que la estancia objeto de estudio era un espacio extra-forense, quizá una vivienda privada.

Sin embargo, los trabajos llevados a cabo mostraron una gran sala de $12,94 \mathrm{~m}$ de longitud y $9,96 \mathrm{~m}$ de anchura, en cuyo lado oriental quedaban aún dos basas de pedestal (59 x 58 $\mathrm{cm}$ de apoyo) y una tercera desplazada, restos

\footnotetext{
${ }^{3}$ Dè la excavación de este sector se hizo cargo la arqueóloga $D^{a}$ Amanda Marcos con la coordinación sobre el terreno de la Dra. Rosario Cebrián. Los cuidados preliminares de la estatua fueron llevados a cabo por los restauradores $\mathrm{D}$. Rafael Taríon, $D^{a}$ Teresa Rovira y $D^{a}$ Olivia Merelo; el dibujo del alzado de la estancia es obra de $D^{a}$ Mónica Martínez y $D$. Diego Ruiz.
} 


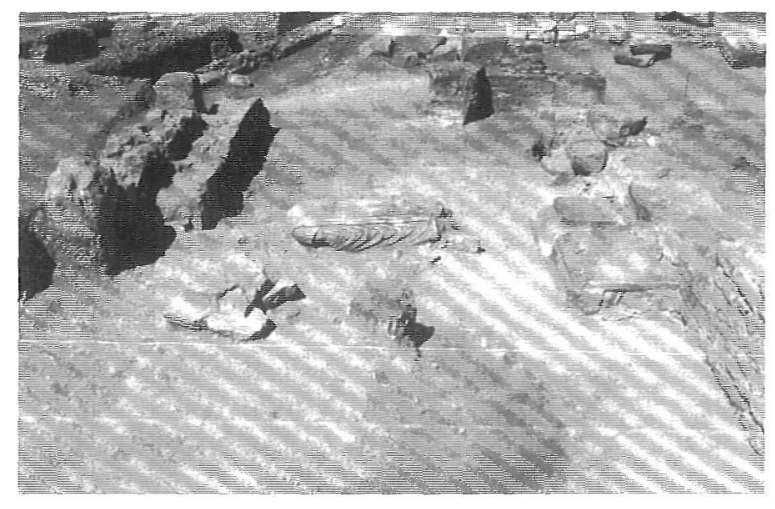

Figura 9. Vista general de la zona del hallazgo al término de la excavación.

de un pedestal epigráfico y una estatua masculina togada que había servido de cimiento a una edificación privada posterior.

La excavación de todo el recinto puso al descubierto nuevos apoyos de pedestales, hasta completar un total de cinco, y nuevos fragmentos de figuras togadas que no han podido ponerse en relación entre sí; en el mismo espacio se recuperaron algunos fragmentos de fuste acanalado, fustes lisos y parte del entablamento decorado con denticulos. En el costado oriental apareció un pequeño umbral de acceso de $1,50 \mathrm{~m}$ de anchura, aunque la estancia debía ser visible desde la sala levantada sobre el criptopórtico que hasta ahora venía siendo considerado como la basílica forense en sí misma.

La estancia está construida en opus uitatum y de su pavimento sólo queda una lechada caliza sobre los niveles de regularización del terreno, pues el pavimento original debió ser arrancado de antiguo en alguno de los numerosos reempleos posteriores de este espacio documentados por la excavación.

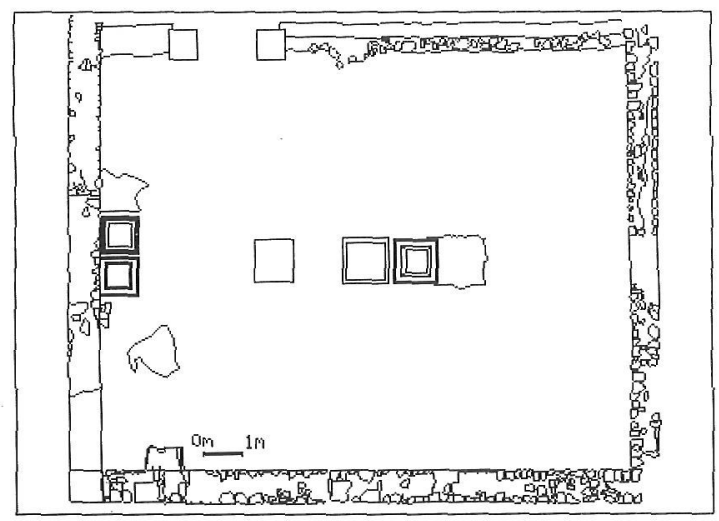

Figura 10. Plano de la estancia con indicación de la posición de los pedestales.

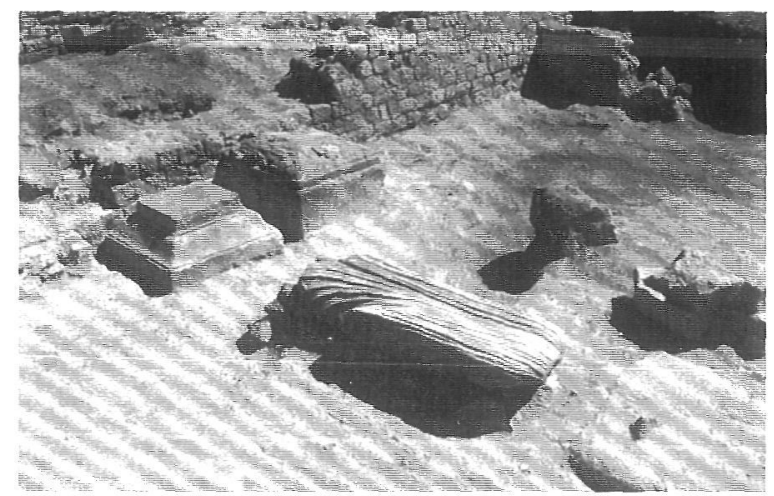

Figura 11. Detalle del hallazgo.

El togado debió caer de su pedestal en fecha no determinable y fue reempleado como base de un muro tardío, quizá ya en época tardorromana a juzgar por la secuencia de las estructuras ahora conocidas en el recinto. La única evidencia de esa caída es la rotura de los pies y del scrinium lateral, mientras la cabeza debió desprenderse de su emplazamiento y ser robada posteriormente en el curso de las excavaciones y expolios de que fue objeto el área durante el Renacimiento.

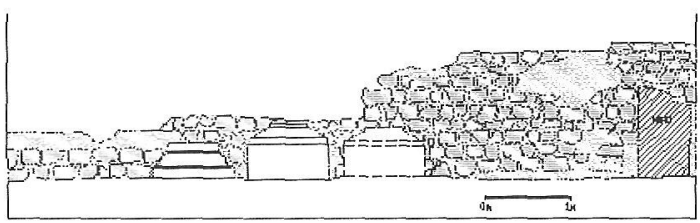

Figura 12. Alzado del muro meridional del lugar de hallazgo con la situación de tres de los pedestales.

\section{II.2. Descripción y estado de conservación}

El togado se encuentra bien conservado, en términos generales, con la salvedad de la rotura de los pies ya citada. Su parte frontal está menos dañada por haber permanecido boca abajo durante siglos en los cimientos mencionados, mientras que la parte posterior presenta algunas erosiones.

La figura tiene en su parte superior una oquedad para insertar la cabeza, lo que permitía sustituir la identidad del personaje representado; esta práctica, conocida en Roma, había sido objeto de no pocos problemas durante el reinado de Tiberio (TÁc. Ann. 74,3; Suet. Tib., 58). A ambos lados de esta oquedad se interrumpe la toga, que originalmente cubría la cabeza.

La figura masculina se encuentra de pie $y$ de frente, descansando el peso del cuerpo 


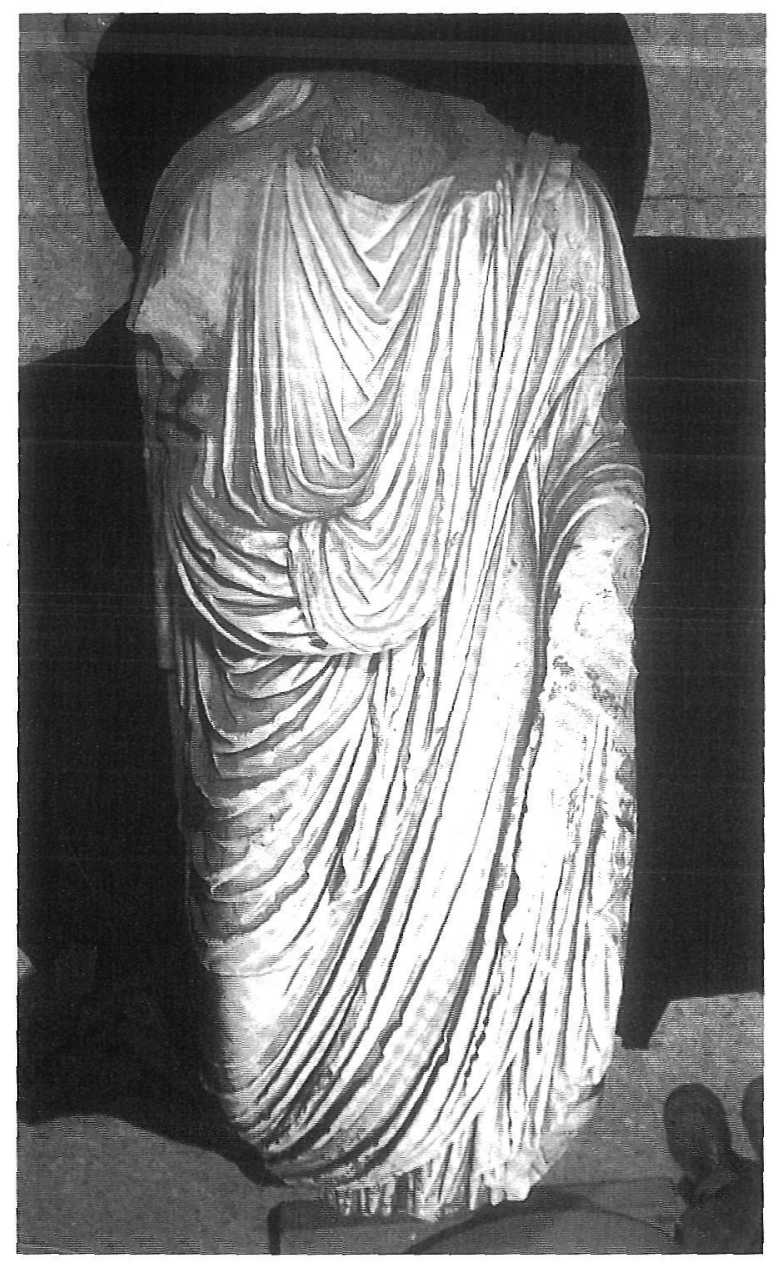

Figura 13. Togado de Segobriga; vista frontal.

sobre su pierna izquierda, y con la derecha ligeramente flexionada, hasta el punto de que la toga deja entrever esa postura con la ausencia de pliegues allí donde queda marcada la rodilla. El brazo izquierdo está doblado, posiblemente en ángulo recto hacia delante, mientras el derecho quedaba algo separado del cuerpo o se rompió en fechas posteriores a la de su colocación, pues hubo de insertarse una espiga de hierro para fijarlo a la estatua; precisamente por ahí se produjo la nueva rotura, de modo que esta pieza hoy no se conserva.

La toga cae de forma oblicua hacia la pierna derecha, y se anuda por encima de la cintura; destaca el cuidadoso tratamiento de los pliegues, muy aristados y profundos, resueltos con menor elegancia en la parte posterior. La figura se partió por la parte inferior de la toga, perdiendo los pies, pero conserva la mitad superior del scrinium representado junto al pie izquierdo, que al mismo tiempo servía para dar estabilidad a la imagen. Las dimensiones actuales de la escultura son $172 \mathrm{~cm}$ de altura, 60 $\mathrm{cm}$ de anchura y $37 \mathrm{~cm}$ de grosor.

\section{II.3. Identificación y cronología}

La nueva figura togada viene a engrosar el número de éstas que ya habían sido descubiertas en Segobriga hasta la fecha en las excavaciones del teatro (BLÁZQUEZ, 1965; ALMAGRO BASCH, 1983a). Sin embargo, el lugar de hallazgo determina una importante diferencia, pues el nuevo ejemplar fue recuperado en la misma estancia en que se situó en origen y ahora sabemos que el espacio estaba ocupado por varias figuras más, de las que sólo tenemos fragmentos de pliegues de ropa y las basas en que se sostenían.

La presencia del velo en la figura circunscribe el hallazgo a la vida pública de Segobriga, descartando la representación de un particular en su propio espacio doméstico al modo que conocemos en otras ciudades (BALTY 1991, p. 18). Cabría la posibilidad de que se tratara de un pontífice, pero la sala de la que procede incluía al menos otras cuatro figuras, lo que obliga a considerar el togado como parte de un programa más amplio que sólo puede tener carácter dinástico.

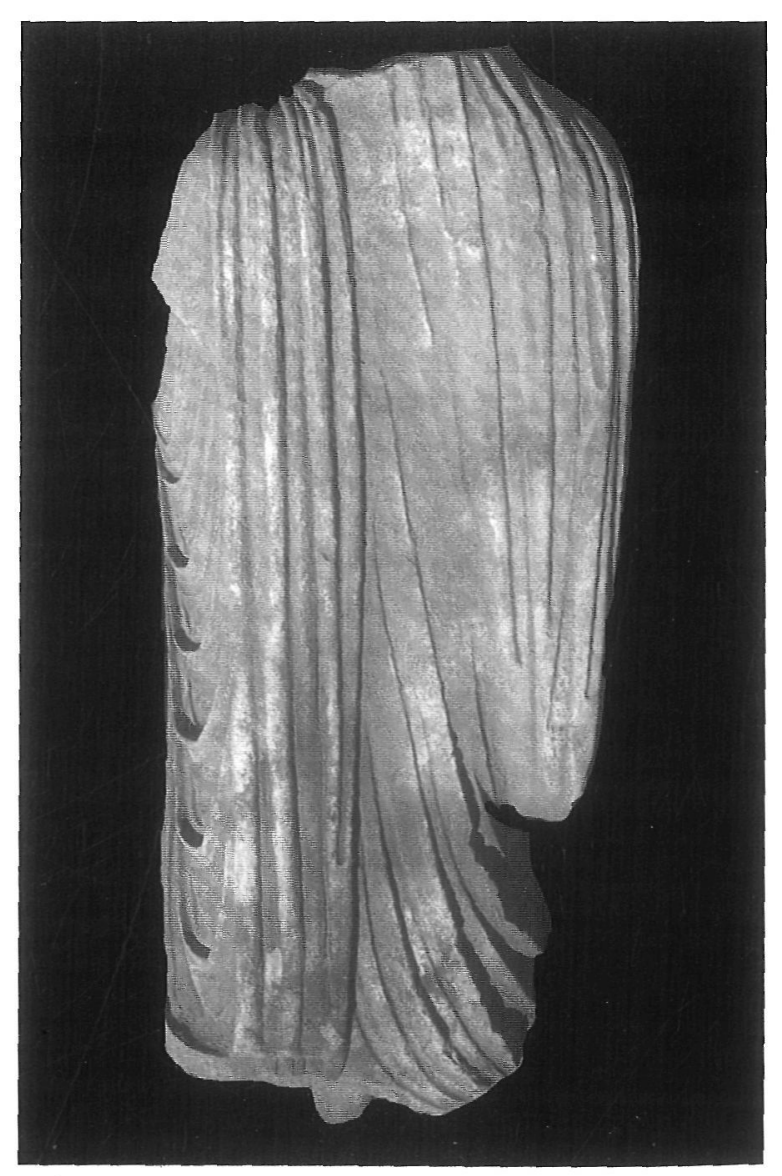

Figura 14. Togado de Segobriga; vista dorsal. 


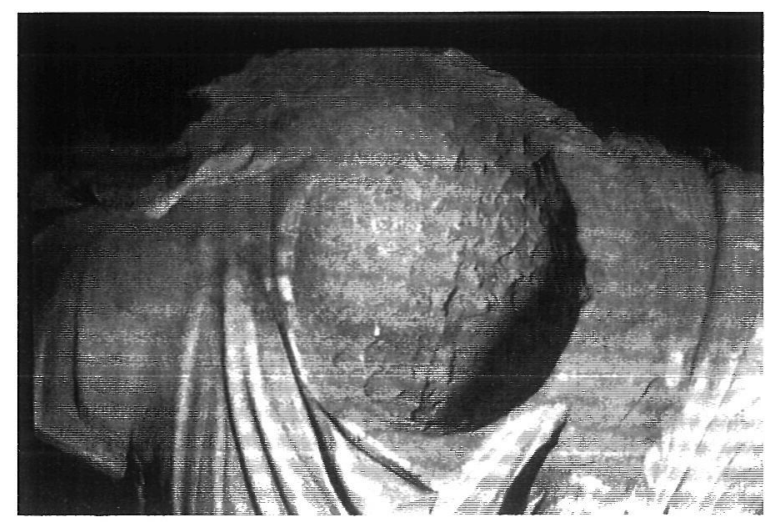

Figura 15. Togado de Segobriga; detalle del cuello.

Las características de la figura, el tipo de pliegues y la posición de la rodilla derecha aconsejar fechar la imagen en los años centrales del siglo I d.C. ${ }^{4}$. Sus referentes formales directos pueden encontrarse en el conjunto escultórico y epigráfico de la basílica de Velleia (SALETTI 1968; GOETHERT 1972; COGITORE 1992, pp. 838 s y 858 s.; ROSE 1997, pp. 121-126, Cat. $50)$, que representa a gran parte de los JulioClaudios y cuya primera etapa fue ejecutada en época de Calígula; en este conjunto, conservado en el Museo Nazionale di Antichità en Parma, las imágenes de Germánico, Tiberio Gemello, Druso III y Augusto (ROSE 1997, lám. 137, 139, 145 y 146) guardan una extraordinaria similitud entre sí y definen un estilo al que bien puede pertenecer la nueva imagen de Segobriga, cuyo tratamiento de la toga permite una fácil clasificación formal (GOETTE 1990, pp. 32-33).

Según esto, el togado de Segobriga no debería distanciarse mucho en el tiempo del retrato de Agrippina Maior que ya hemos presentado y que fue descubierto a escasos metros, aunque en otro recinto. El personaje representado debe ser un miembro de la familia julio-claudia, y el togado formaría parte de un programa dinástico de los que sabemos que se popularizaron en algunas ciudades entre las que se encuentra Segobriga (RODÀ 1998, pp. 121-122), aquí especialmente visible desde el reinado de Calígula .

A partir del año 37 d.C. el Emperador se ocupó personalmente y con gran eco entre la opinión pública de restituir el honor y la imagen de su madre y sus hermanos (DIO, 59, 3; SUET. Gaius, 15), pero también asumió la restauración de la imagen pública de los JulioClaudios, especialmente de aquellos miembros de la familia que habían sido asesinados o condenados durante el reinado de Tiberio; todo ello debe considerarse parte del programa destina- do a restaurar un orden dinástico en el que el mismo Calígula tuviera una posición clara, utilizando para ello el prestigio que tenía como hijo de Germánico, al que había acompañado de niño (ROSE 1997, pp. 32-38).

No es posible determinar si el togado representa a un miembro de la familia anterior a Calígula o si se trata de una figura añadida durante su reinado o en los primeros años del de Claudio, máxime teniendo en cuenta de que tampoco hay garantías para fechar con precisión el retrato de Agrippina en una u otra etapa.

Llegados a este punto es necesario citar que junto al togado, y entre los escombros de nivelación de las fases posteriores del edificio, se recuperaron varios fragmentos de un pedestal epigráfico que conserva íntegro su costado derecho; está realizado en piedra caliza local de las cercanas canteras situadas junto al santuario rupestre de Diana, que se explotan al menos durante las primeras décadas del Principado. El togado y la inscripción fueron reempleados como materiales de relleno y ni-

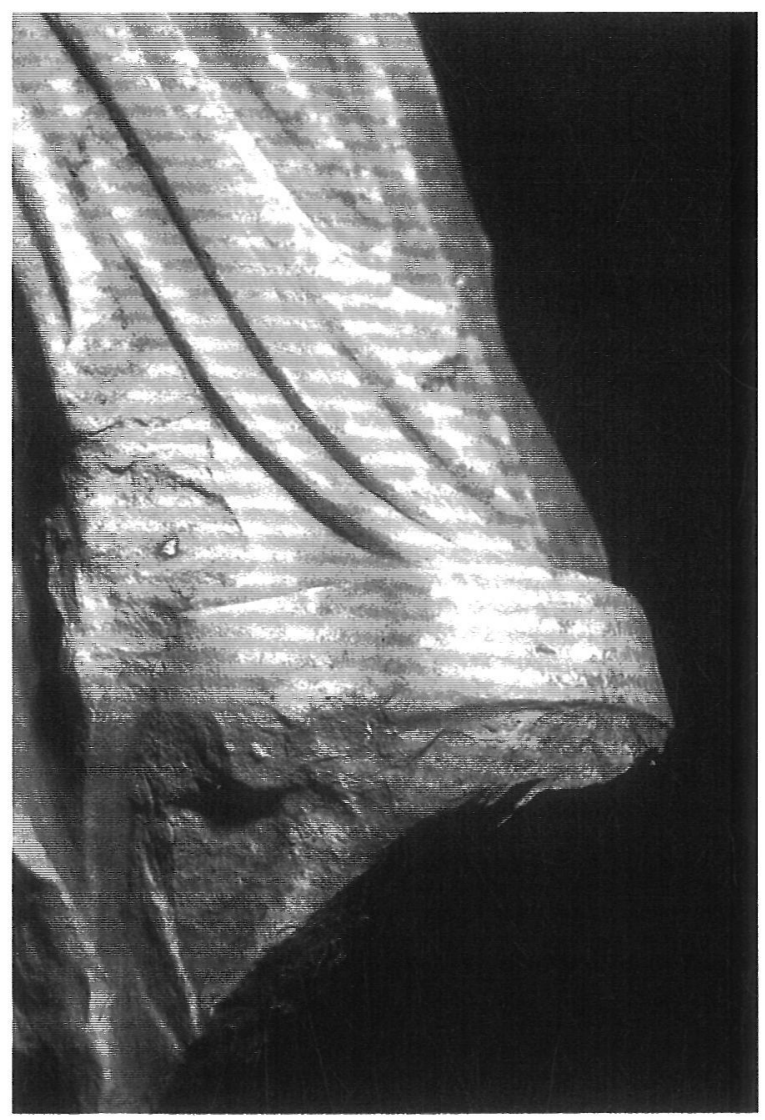

Figura 16. Togado de Segobriga; scrinium.

\footnotetext{
${ }^{4}$ Agradecemos al Dr. José Luis Jiménez Salvador (Universidad de Valencia) sus observaciones a este respecto.
} 


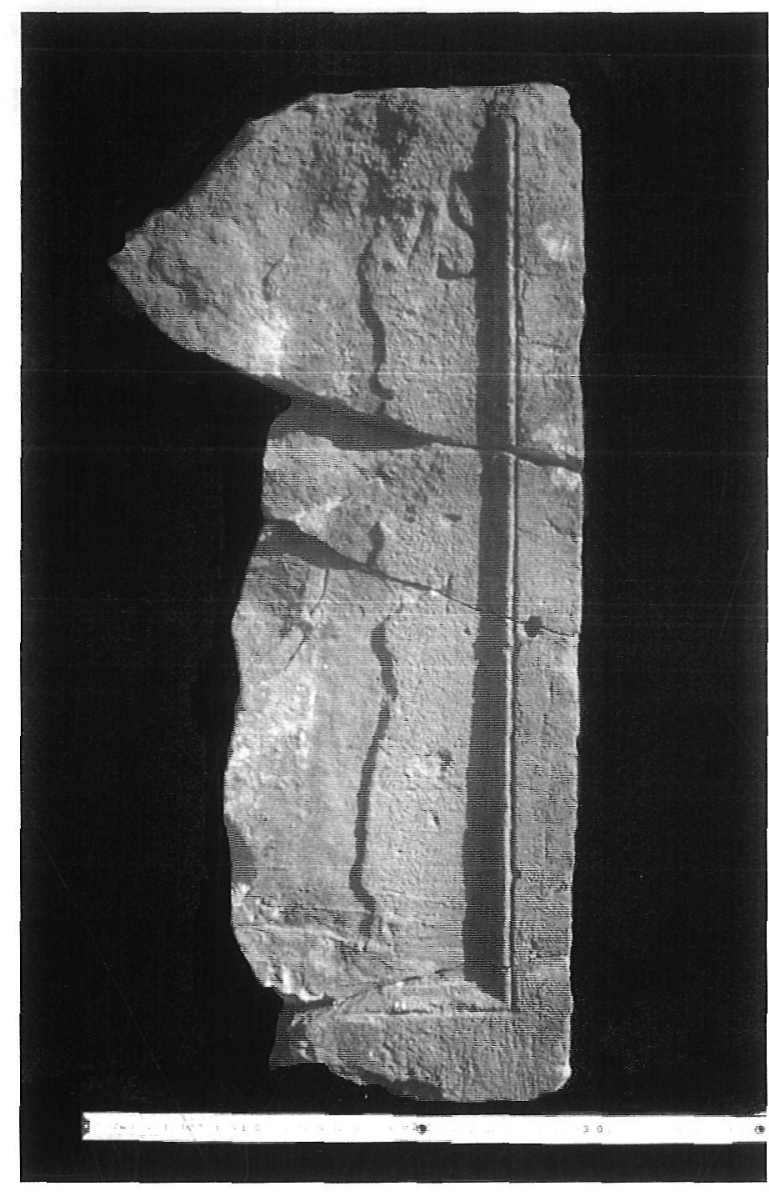

Figura 17. Pedestal con inscripción aparecido junto al togado.

velación en un mismo momento y formaban parte de la decoración original de la estancia; en la que había apoyos para cinco pedestales incluido el que nos ocupa.

El pedestal presenta una moldura lateral plana en tres de sus lados, separada de la cartela por varias molduras curvas hasta completar un ancho de $5,5 \mathrm{~cm}$, quedando libre el borde superior; sobre éste iría emplazado un coronamiento exento que soportaría la estatua correspondiente, probablemente la misma que se encontró junto a él. El campo epigráfico está rebajado y alisado. Sus dimensiones actuales son $61 \times[27] \times[25,5] \mathrm{cm}$ y la basa de la que cayeron el pedestal y la estatua tiene una superficie de apoyo de $59 \times 58 \mathrm{~cm}$, por lo que el pedestal era casi cúbico, con unas medidas de circa $61 \times 58 \times 58 \mathrm{~cm}$; la simetría de la moldura permite suponer que el ancho disponible para escritura en la cartela era de unos $47 \mathrm{~cm}$. Sólo conserva las dos últimas letras de la primera línea; la primera de estas letras mide $3,4 \mathrm{~cm}$ y la segunda $5,8 \mathrm{~cm}$.

En toda la inscripción, por debajo de la primera línea queda espacio para texto, sin que exista huella alguna de él. La única explicación posible es que las posibles líneas inferiores tuvieran un escaso número de letras grabadas con una paginación centrada. El reducido tamaño del pedestal y esta circunstancia obliga a aceptar que el texto tan sólo contenía una identificación de la figura que soportaba el pedestal, es decir, un nombre propio en nominativo en la primera línea, seguido de un título breve en la segunda.

En el texto hoy sólo puede leerse lo siguiente:

\section{$[$ - $] V S$ \\ $[-]$}

No es posible restituir la parte perdida del texto, pero el cálculo de espacios permite suponer unas $7 / 8$ letras en la parte izquierda de la línea, por lo que cabría cualquier nombre imperial seguido en la segunda línea de un título como Caes(ar); en todo caso, el uso del nominativo y las escasas letras conservadas aconsejan se cautos en la restitución del texto.

\section{LA IMAGEN DINÁSTICA DE LOS JULIO- CLAUDIOS EN SEGOBRIGA}

Desde hace más de 500 años se conoce la existencia en Uclés de dos pedestales honoríficos que deben pertenecer a la larga serie de monumentos trasladada desde Segobriga como material de cantería para la construcción del monasterio (ALFÖLDY 1987, p. 78); en los pedestales, hoy perdidos, se honraba la memoria de Germánico y Druso, los hijos de Tiberio muertos en los años 19 y 23 d.C. El dedicante, el edil L. Turellius Geminus, erigió estas estatuas a Germánico y Druso entre los años 12 y 14 d.C. (CIL II 3103 y 3104). Sabemos por Tácito, y lo confirma la Tabula Siarensis y otros documentos epigráficos, que el Senado decretó a la muerte de ambos los honores que habían de tributarles las ciudades del Imperio (DEMOUGUIN, NICOLET, RICHARDSON y CRAWFORD en CRAWFORD 1996, pp. 507-547), de lo que existen hoy numerosas evidencias. Pero en muchas ciudades, ambos fueron honrados en vida en el marco de los programas epigráficos para la familia imperial que llenaron los foros municipales y coloniales.

También de Segobriga procede el fragmento de un tercer pedestal, esta vez en honor de Tiberio, datado por su titulatura entre los años 17 y 18 d.C. (ALMAGRO BASCH 1984, nº 30; 
ALFÖLDY 1987, p. 80), conservado hoy en el Museo de las excavaciones. Una cuarta evidencia de este programa la constituye un fragmento de pedestal dedicado a Claudio en el año 43 d.C. y hoy perdido (CIL II 3105; ALMAGRO BASCH 1984, n² 27; ALFÖLDY 1987, p. 81).

A este serie habría que añadir ahora un quinto fragmento de otro pedestal en caliza local, descubierto accidentalmente entre las terreras antiguas durante la excavación de un tramo oriental de la muralla en 1999, en el que puede verse parte de una titulatura imperial (Figura 18); el fragmento ${ }^{5}$ mide [12] $x$ [27] $x$ [21] $\mathrm{cm}$ y conserva parte de una línea de texto con letras de $6,5 \mathrm{~cm}$ de altura. En el texto sólo puede leerse lo siguiente:

\section{[- Au]g(usto) - Germ(anico) [-].}

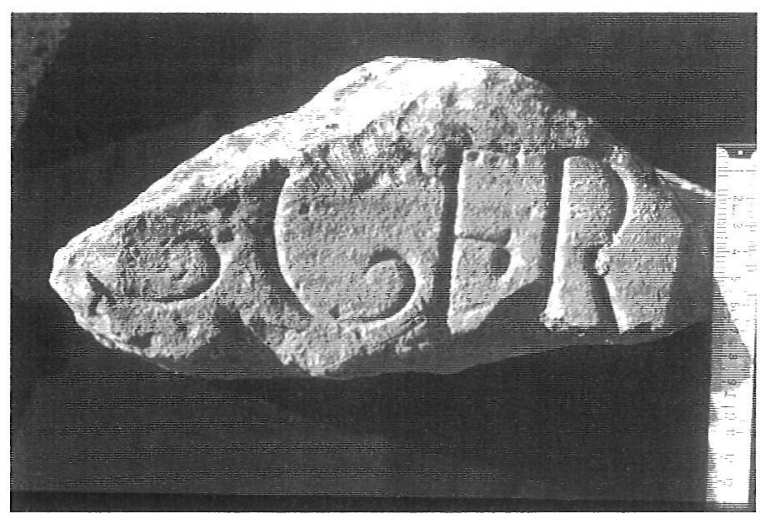

Figura 18. Fragmento de pedestal con parte de una titulatura imperialLa forma de la letra $G$, repetida en la línea, curvada y cerrada en espiral en su parte inferior, se data a mediados del siglo I d.C. en la Bética (Cfr. CIL II2/7, 278 y 498) y esta cronología podría servir también para este pedestal segobrigense. No es posible identificar al destinatario del homenaje que, en todo caso, podría ser Claudio si atendemos a la cronología del soporte y a la titulatura conservada.

A esta serie habría que añadir los testimonios sobre la existencia de unos sodales Claudiani en Segobriga; de ellos sólo tenemos noticia en inscripciones funerarias ${ }^{6}$, pero deben considerarse la evidencia de un culto dinástico en honor de la familia en la propia ciudad.

A esta larga serie de referencias epigráficas vienen a sumarse ahora los descubrimientos escultóricos de los que tratan estas notas. La primera impresión que uno tiene a la vista de esta documentación es que en la ciu- dad, como en otros muchos municipios y colonias del Imperio, existió un culto imperial bien desarrollado del que tenemos además otros muchos testimonios en Segobriga para otros períodos.

Sin embargo, si la ciudad había homenajeado a Germánico y Druso en vida, incluso antes de que el Senado romano decretara los honores post mortem, y si había hecho lo propio con Tiberio unos años después, es porque Segobriga tenía una deuda directa con los julio-claudios, derivada de la concesión del privilegio municipal en época de Augusto. A lo largo de toda la primera mitad del siglo I d.C. se sucedieron los testimonios de gratitud hacia la familia, que dieron lugar a las evidencias epigráficas ya citadas y que permiten hablar de un auténtico culto dinástico.

Aunque desconocemos cuál fue el emplazamiento original de los perdidos pedestales de Druso y Germánico que fueron vistos en Uclés hace varios siglos, sabemos que la estatua togada y velada se encontraba en una sala con otros pedestales, cerca de la cual apareció la cabeza de Agrippina Maior. Dado que la estancia sólo tuvo cinco pedestales, los otros tres debieron sostener también estatuas de otros miembros de la familia, por lo que el espacio debió ser una sala de culto dinástico para los julio-claudios, que no debe llamar la atención en una ciudad que llegó a tener, precisamente, unos sodales Claudiani.

\section{BIBLIOGRAFÍA}

ABASCAL, J.M. 2000: «Elites y sociedad romana en la Meseta sur», en Epigrafía y sociedad en Hispania durante el Alto Imperio: estructuras y relaciones sociales. Mesa redonda, Madrid, abril 2000 (e.p.).

ALFÖLDY, G. 1987: Römisches Städtewesen auf der neukastilischen Hochebene. Ein Testfall für die Romanisierung. Heidelberg.

ALMAGRO BASCH, M. 1983a: "Las esculturas de togados halladas en la escena del teatro romano de Segóbriga", AEA 56, 131-150.

ALMAGRO BASCH, M. 1984: Segobriga II. Inscripciones ibéricas, latinas paganas y latinas cristianas. EXcavaciones Arqueológicas en España 127. Madrid.

\footnotetext{
${ }^{5}$ Inv. 99/006/126, conservado en el Museo de Segobriga.

${ }^{6}$ Los sodales Claudiani aparecen entre los dedicantes de dos inscripciones funerarias; en la primera de ellas, hoy perdida, se dice que estos sod(ales) Claudiani cont(ulerunt) ad funus de T. Octauius Saturninus (CIL II 3114; ALMAGRO BASCH 1984, $n^{\circ}$ 57; ALFÖLDY 1987, p. 77); en la segunda, conservada en el Museo de Segobriga, aparecen como dedicantes del monumento de Baebia Calybe (CIL II 5879; ALMAGRO BASCH 1984, n 58; ALFÖLDY 1987, p. 77).
} 
ALMAGRO GORBEA, M. y ABASCAL, J.M. 1999: Segobriga y su conjunto arqueológico. Madrid.

BALTY, J.CH. 1991: Porträt und Geselschaft in der römischen Welt. Mainz 1991.

BLÁZQUEZ, J.M ${ }^{a}$ 1965: «Esculturas romanas de Segóbriga», Zephyrus 16, pp. 119-126.

BOSCHUNG, D. 1993: «Die Bildnistypen der iulischclaudischen Kaiserfamilie: ein kritischer Forschungsbericht", JRA 6, 39-79.

COGITORE, I. 1992: "Séries de dédicaces italiennes à la dynastie julio-claudienne", MEFRA 104, pp. 817-870.

CRAWFORD, M.H. (ed.) 1996: Roman Statutes. Londres.

FITTSCHEN, K. y ZANKER, P. 1983: Katalog der römischen Porträts in den Capitolischen Museen und den anderen Kommunalen Sammlungen der Stadt Rom. Mainz.

GOETHHERT, K.P. 1972: "Zur Einheitlichkeit der Statuengruppe aus der Basilika con Velleia", RM 79, pp. 235247.

GOETTE, H.R. 1990: Studien zur römischen Togadarstellung. Mainz.

HERTEL, D. 1981: «Eine claudisches Frauenporträt in Faro/ Portugal», MDAl(M) 22, pp. 255-267.

JUCKER, H. 1980: «Zum Carpentum-Sesterz der Agrippina Maior", en Forschungen und Funde. Festschrift $B$. Neutsch. Innsbruck, pp. 205-217.

LICHOCKA, B. 1984: «Les portraits d'Agrippina major sur les monnaies romaines", RoczMuzWarsz 28, pp. 733.

LICHOCKA, B. 1986: «Les monnaies d'Agrippine Major et une hybride barbare", Proceedings of the 10th
International Congress of Numismatics. Londres, pp. 181-184.

POLASCHEK, K. 1973: Porträttypen einer claudischen Kaiserin. Roma.

RODÀ, I. 1998: “Espacios de representación y de culto dinástico en la provincia de Hispania citerior», Histria Antiqua 4, pp. 117-126.

ROSE, CH.B. 1997: Dynastic Conmemoration and Imperial Portraiture in the Julio-Claudian Period. Cambridge.

SALETTI, C. 1968: Il ciclo statuario de la basilica di Velleia. Milán.

SHOTERR, D. 2000: “Agrippina the Elder. A Woman in a Man's World, Historia 49.3, 341-357.

TÖLLE-KASTENBEIN, R. 1974: Samos 14. Das Kastro Tigani. Die Bauten und Funde griechischer, römischer und byzantinischer Zeit. Bonn.

TANSINI, R. 1995: I ritratti di Agrippina Maggiore. Rivista di archeologia, suppl. 15. Roma.

TRILLMICH, W. 1978: Familienpropaganda der Kaiser Caligula und Claudius. Agrippina Maior und Antonia Augusta auf Münzen. Antike Münzen und Geschnittene Steine 8. Berlín.

TRILLMICH, W. 1984: «Beobachtungen am Bildnis der Agrippina Maior oder: Probleme und Grenzen der 'Typologie'», MDAl(M) 25, pp. 135-158.

WOOD, S. 1988: «Memoriae Agrippinae: Agrippina the Elder in Julio-Claudian Art and Propaganda", AJA 92.3, pp. 409-426. 